\title{
A LÍNGUA PORTUGUESA EM CONCURSOS PÚBLICOS DA ÁREA DE GESTÃO EMPRESARIAL: UM ESTUDO QUANTITATIVO
}

\author{
Diego C. Ribeiro, Raquel Tiemi Masuda Mareco \\ Faculdade de Tecnologia do Estado de São Paulo - Fatec, Curso de Gestão Empresarial - EAD, Presidente Prudente, \\ SP.E-mail: diegocr.ads@gmail.com
}

\begin{abstract}
RESUMO
A língua portuguesa é uma disciplina que está presente em todos os concursos, sendo essencial que o candidato se saia muito bem nessa matéria para que consiga a aprovação. Entretanto, além de ser disciplinado para estudar, o candidato precisa saber o que estudar de cada disciplina. Pensando nisso, o objetivo desta pesquisa quantitativa foi levantar as recorrências de conteúdos nas provas de língua portuguesa de concursos nacionais. Para tanto, contamos com 17 provas de concursos cujos editais foram publicados de 2012 a 2015. A análise demonstrou que a intepretação de textos é o conteúdo mais recorrente nas provas dos concursos analisados, seguido de significação de palavras e análise sintática. Concluímos que, mesmo tendo a interpretação de textos como o conteúdo mais recorrente, se somarmos todos os conteúdos que exigem um conhecimento de gramática, terá maior probabilidade de aprovação nesses concursos, o candidato que estudar aspectos gramaticais da língua.
\end{abstract}

Palavras-chave: língua portuguesa, concurso, gestão empresarial.

\section{PORTUGUESE LANGUAGE IN PUBLIC CONTESTS FOR BUSINESS MANAGEMENT: A QUANTITATIVE STUDY}

\begin{abstract}
Portuguese language is a subject that is in all contests, being essential that the candidate goes very well in this subject not to fail in the exam. However, besides being organized to study, the candidate must know what to study in which subject. Thus, the objective of this quantitative research was to list recurrences of contents in Portuguese language test of national contests. We analyze 17 contests exams published between 2012 and 2015. The analysis has shown that text interpretation is the most recurrent content, followed by word meaning and syntactic analysis. We concluded that, even text interpretation being the most recurrent content, when we add up all the contents which requires grammar knowledge, we can notice that the candidate who studies grammar aspects will have more probability or succeeding.
\end{abstract}

Keywords: Portuguese language, contest, business management. 


\section{INTRODUÇÃO}

A estabilidade oferecida por um cargo público tem feito com que a concorrência nos concursos públicos aumentasse a cada ano. Muitos dos que já possuem um emprego, buscam estudar e se aprimorar para alcançar uma vaga em um órgão público. Nesse contexto, o curso de Gestão Empresarial oferece várias possibilidades, pois abre uma grande variedade de cargos que o profissional pode concorrer.

A aprovação em um concurso público depende de vários fatores, dentre eles organização, disciplina e dedicação com os estudos. Além de estudar, o candidato precisa saber o que estudar de cada disciplina. A língua portuguesa é uma disciplina básica, que está presente em todos os concursos, sendo essencial que o candidato se saia muito bem nessa matéria para que consiga a aprovação.

Embora muitos estudiosos defendam que não se deve ensinar gramática na escola, veremos, mais adiante neste trabalho, que o domínio de questões gramaticais oferece vantagens na concorrência por uma vaga em um emprego público. Em relação à isso, Possenti (1996, p. 17) afirma que

O objetivo da escola é ensinar o português padrão, ou, talvez mais exatamente, o de criar condições para que ele seja aprendido. Qualquer outra hipótese é um equívoco político e pedagógico. A tese de que não se deve ensinar ou exigir o domínio do dialeto padrão dos alunos que conhecem e usam dialetos não padrões baseiam-se em parte no preconceito segundo o qual seria difícil aprender o padrão.

O estudo da gramática não deve iniciar na graduação, mas na educação básica para que, na graduação o aluno possa aprender aspectos específicos da língua aplicados à sua área de atuação. Muitas vezes, o aluno pode julgar que não há necessidade de aulas de língua portuguesa no curso de graduação, mas vemos que cada vez mais ela é cobrada em concurso, tornando um diferencial para o aluno que a domina. Pensando nisso, o objetivo desta pesquisa quantitativa foi levantar as recorrências de conteúdos nas provas de língua portuguesa de concursos nacionais cujos editais foram publicados de 2012 a 2015. Com esse levantamento em mãos, teremos um material organizado para oferecer para professores e alunos, a fim de que ele auxilie em seus estudos, visando à aprovação dos graduandos em concursos públicos.

\section{METODOLOGIA}

Nosso estudo se caracteriza como uma pesquisa quantitativa, pois realizaremos um levantamento de dados que resultarão em planilhas e gráficos (MARCONI; LAKATOS, 2003). A 
partir desses números, teremos embasamento para justificar a necessidade do enfoque ou não em determinados conteúdos e/ou tipo de atividade. Não se trata de uma pesquisa de cunho qualitativo, mas que poderá resultar em ações práticas que alterem a dinâmica de aulas até o momento ou poderá resultar em ações complementares, cursos de extensão, aulas extra, etc., para melhor preparar o aluno para esse tipo de prova.

Para a nossa coleta de dados consideraremos os concursos nacionais cujas provas estejam disponíveis online e cujos editais foram divulgados a partir de janeiro de 2012 até o atual momento. Esse período foi selecionado por ter sido a partir dele que passaram a vigorar as novas normas ortográficas.

Os concursos cujas provas fizeram parte de nosso levantamento estão listados abaixo:

- 2012 - Dataprev

- 2012 - Petrobras

- 2013 - Policia Federal

- 2013 - IBGE (2 concursos no ano)

- 2014 - Petrobras

- 2014 - Anatel

Foram analisadas um total de 105 questões em 17 provas. Observou-se que em concursos para muitos cargos, as questões eram iguais, tendo como diferencial nas provas apenas as questões especificas de cada cargo.

Os dados serão organizados em uma planilha de Excel e, posteriormente, elaboraremos gráficos para melhor ilustrar os resultados da pesquisa.

\section{RESULTADOS}

Iniciamos a apresentação dos resultados com uma visão geral dos conteúdos. Em seguida, apresentamos os conteúdos mais recorrentes em gráficos separados. 


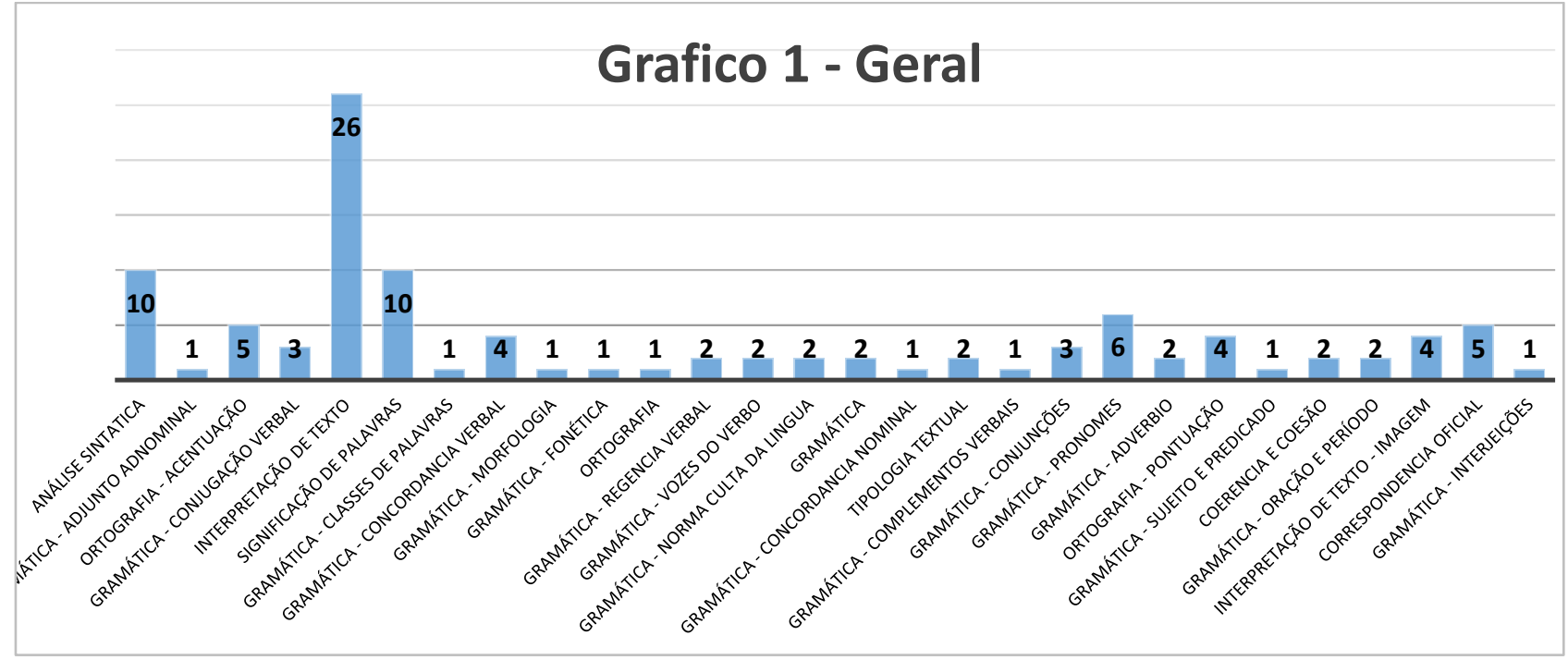

Figura 1. Visão geral da recorrência dos conteúdos dos concursos

A figura 1 demonstra que a intepretação de textos é o conteúdo mais recorrente nas provas dos concursos analisados, seguido de significação de palavras e análise sintática. Na figura seguinte, vemos o percentual de cada conteúdo.

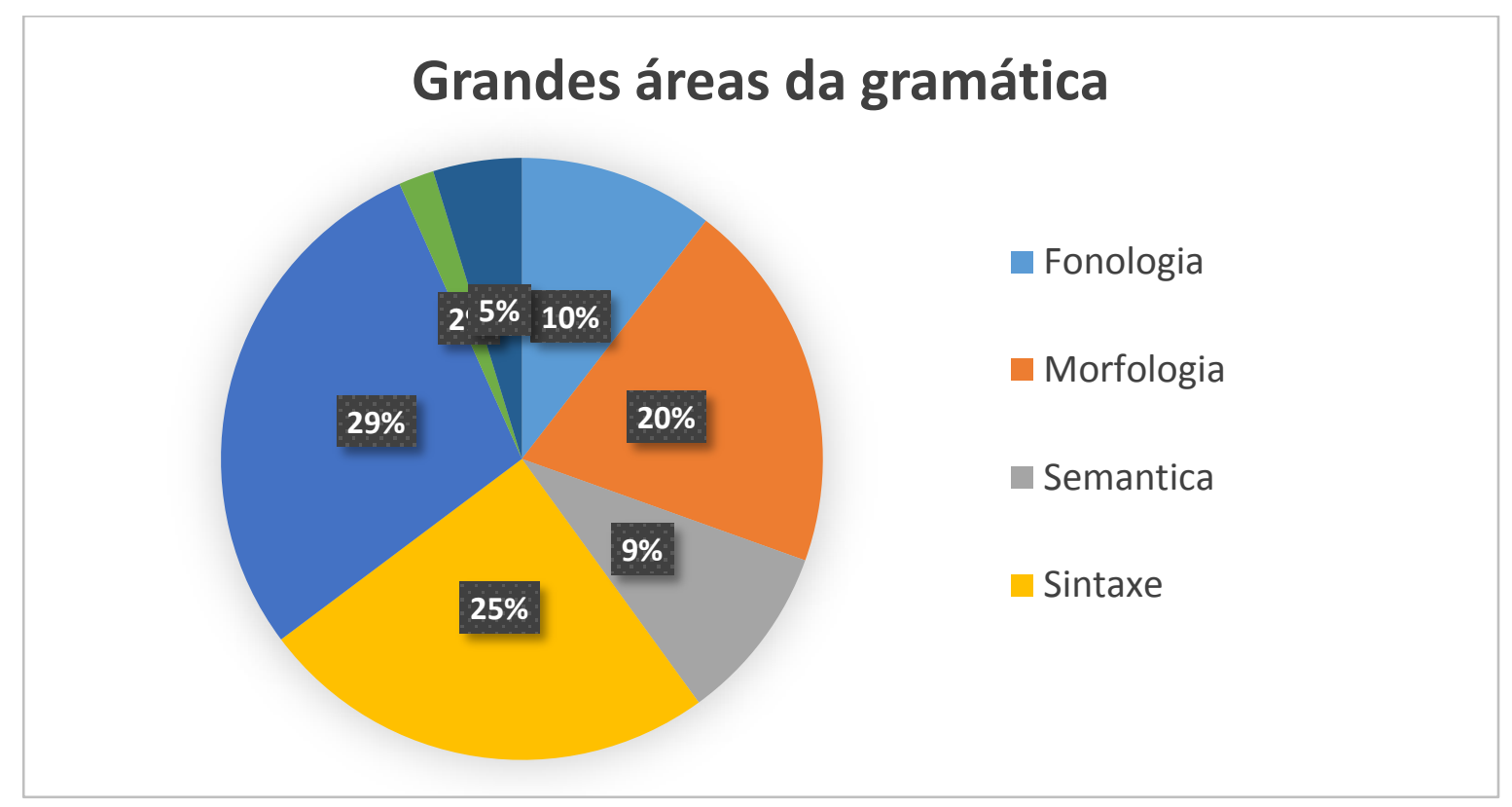

Figura 2. Porcentagem de conteúdos.

Como vemos, os conteúdos com maior percentual foram interpretação de texto, sintaxe e morfologia. Pode-se observar que correspondência oficial, que seria um conteúdo mais específico da área está presente em apenas $5 \%$ das provas de concursos analisadas. Portanto, a gramática 
em geral e a interpretação de textos são os itens que devem ser mais estudados para que se tenha um bom resultado em um concurso nacional relacionado à área de gestão empresarial.

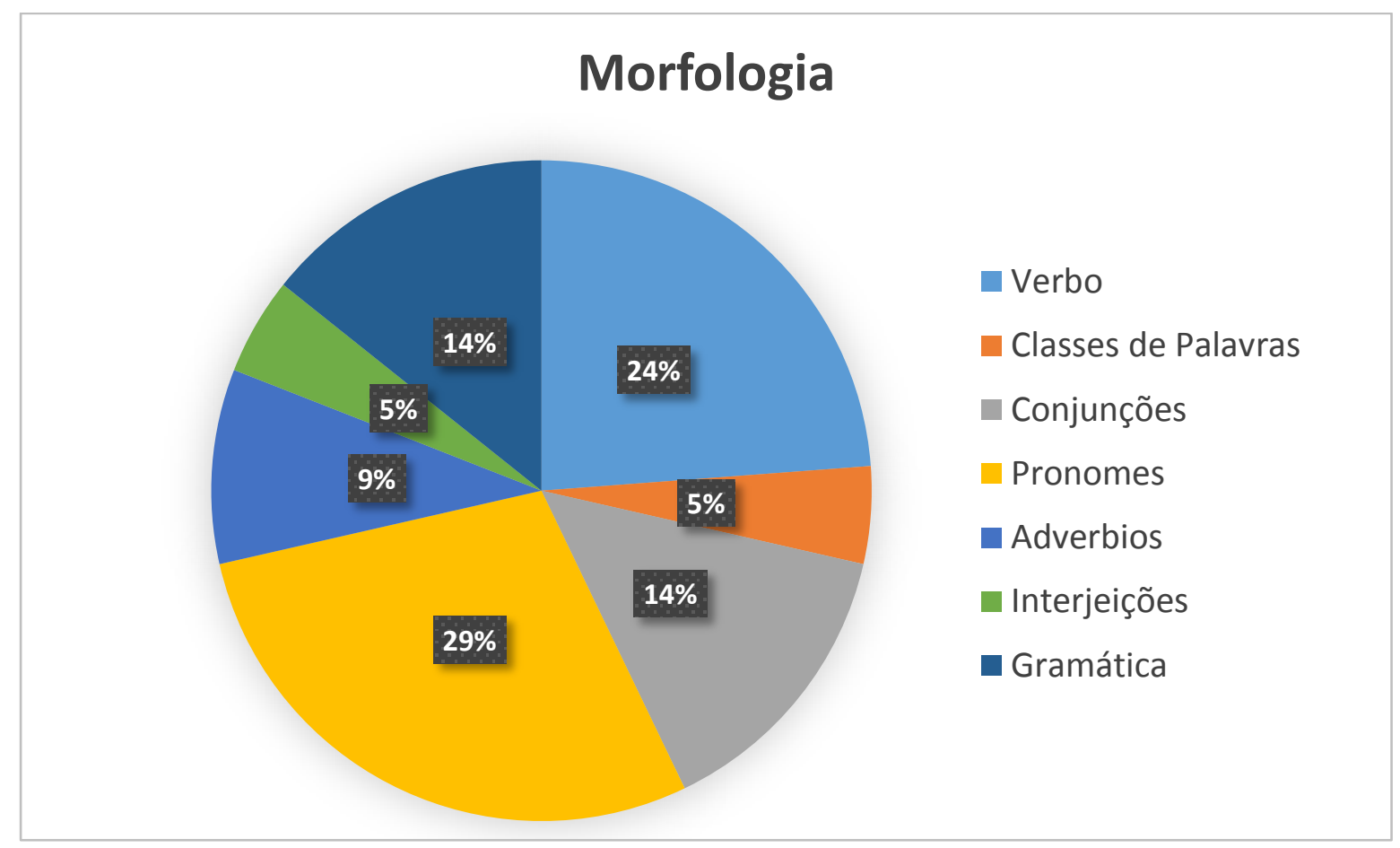

Figura 3. Conteúdos de morfologia.

Dos conteúdos de morfologia, pronomes foi o mais recorrente, seguido de verbos (conjugação, modos e vozes), conjunções e gramática.

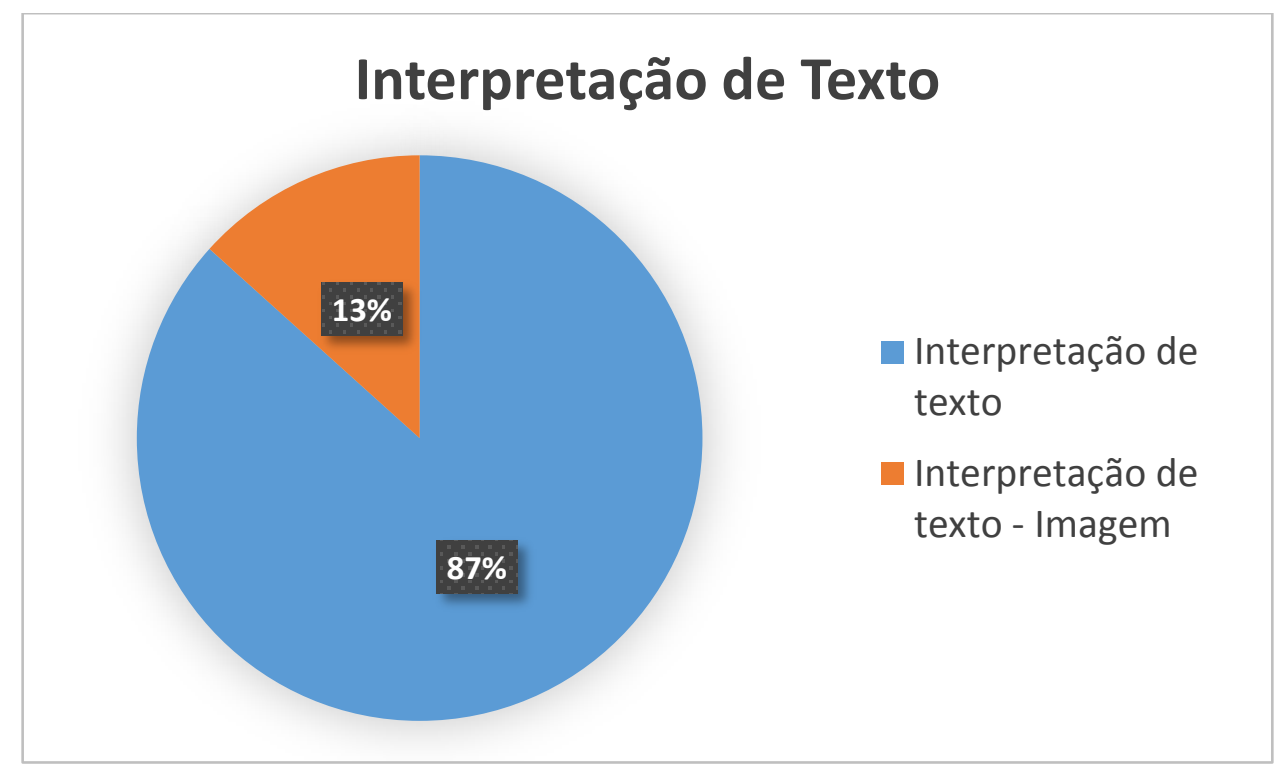

Figura 4. Porcentagem de texto imagético na interpretação textual. 
Considerando as questões relacionadas à interpretação de textos, apenas $13 \%$ tratavam de textos imagéticos, o que demonstra a predominância de textos escritos sobre textos imagéticos (gráfico, figuras, desenhos, etc).

\section{DISCUSSÃO}

Sabe-se que, hoje, os professores de língua portuguesa atuantes na educação básica são incentivados a privilegiar a interpretação e a produção de textos sobre a gramática. Mas, isso não significa que não se deve ensinar gramática.

A interpretação de textos é algo que exige prática. O professor pode fornecer dicas e/ou estratégias, mas o olhar, a interpretação só se aperfeiçoa com a prática e com leituras. $\mathrm{O}$ aluno de graduação tem mais autonomia e responsabilidade sobre seus estudos e pode, também, estudar gramática e praticar interpretações de textos fora da sala de aula. Pensando nesses alunos interessados em prestar concursos públicos, fizemos o presente levantamento. Com ele, o aluno pode direcionar seus estudos para conteúdos mais prováveis de estarem em uma prova desse tipo.

Por mais que se tente priorizar a interpretação de textos sobre os conteúdos gramaticais na educação básica e no ensino superior, ao se deparar com uma prova de concursos, o conhecimento mais cobrado será sobre o conteúdo gramatical.

\section{CONCLUSÃO}

Por meio dos resultados e da discussão apresentados, podemos perceber que, apesar de na educação básica a disciplina de língua portuguesa buscar um enfoque na interpretação de textos e nos cursos de graduação ela ser trabalhada de maneira contextualizada, conseguirá mais pontuação em provas de concursos, considerando as provas analisadas, os indivíduos que tiveram uma boa base gramatical.

Portanto, concluímos que, mesmo sendo a interpretação de textos o conteúdo mais recorrente, se somarmos todos os conteúdos que exigem um conhecimento de gramática, constatamos que terá maior probabilidade de aprovação nesses concursos, o candidato que estudar aspectos gramaticais da língua. 


\section{REFERÊNCIAS}

MARCONI, M. A.; LAKATOS, E. M. Fundamentos da metodologia científica. 5. ed. São Paulo: Atlas, 2003.

POSSENTI, S. Porque (não) ensinar gramática na escola. São Paulo-SP; Mercado das Letras, 1996. 